\title{
Consumption of obesogenic foods in non-Hispanic black mother-infant dyads
}

\author{
Melissa C. Kay ${ }^{1}$ [D । Heather Wasser ${ }^{1}$ । Linda S. Adair ${ }^{1}$ | Amanda L. Thompson ${ }^{1,2}$ । \\ Anna Maria Siega-Riz ${ }^{1,3}$ | Chirayath M. Suchindran ${ }^{4}$ | Margaret E. Bentley ${ }^{1}$
}

\author{
${ }^{1}$ Department of Nutrition, University of North \\ Carolina at Chapel Hill, Chapel Hill, North \\ Carolina, USA \\ ${ }^{2}$ Department of Anthropology, University of \\ North Carolina at Chapel Hill, Chapel Hill, \\ North Carolina, USA \\ ${ }^{3}$ Department of Public Health Sciences, \\ University of Virginia, USA \\ ${ }^{4}$ Department of Biostatistics, University of \\ North Carolina at Chapel Hill, Chapel Hill, \\ North Carolina, USA \\ Correspondence \\ Melissa C. Kay, Nutrition Carolina Population \\ Center, University of North Carolina at Chapel \\ Hill, 137 East Franklin St CB 8120, Chapel Hill, \\ NC 27515, USA. \\ Email: MelissaC.RD@gmail.com
}

\begin{abstract}
Obesity continues to be a problem in the United States. Of particular concern is the epidemic of early childhood obesity. A significant predictor of child diet is maternal diet, but little is known about this relationship during infancy. This study examined the association between maternal and infant consumption of key food groups from 6 to 18 months using data from the Infant Care, Feeding, and Risk of Obesity Study, a prospective cohort of 217 non-Hispanic black, low-income, first-time mothers. Using data from 24-hr dietary recalls collected during in-home visits at 6, 9, 12 , and 18 months, we assessed longitudinal associations between mother and child intake of both energy-dense, nutrient-poor (obesogenic) food groups and fibre-, nutrient-rich food groups using random intercept logistic regression. Both mothers and their infants had high intake of sugar-sweetened beverages, desserts, and sweets and low intake of vegetables and whole grains. Infant consumption of key food groups was strongly associated with maternal consumption, suggesting the need for focused interventions to target maternal diet as a pathway to decreasing risk for the establishment of poor dietary patterns early in life.
\end{abstract}

\section{KEYWORDS}

diet, infant nutrition, maternal nutrition, obesity, postpartum

\section{1 | INTRODUCTION}

Childhood obesity continues to be a major public health concern, affecting even the youngest age group of infants and toddlers. Currently, $8.1 \%$ of children under 2 are considered at risk for obesity (weight-for-length 295 th percentile) with rates higher among non-Hispanic black (NHB) children compared to non-Hispanic white children (Dalenius, Borland, Smith, Polhamus, \& Grummer-Strawn, 2012; Freedman, 2011; Ogden, Carroll, Kit, \& Flegal, 2014). Being overweight in the first 2 years of life is associated with obesity and higher risk for chronic diseases in adolescence and adulthood (Baird et al., 2005; Nader et al., 2006; Reilly et al., 2005; Skilton et al., 2013; Stocks et al., 2011; Taveras et al., 2011). Eating patterns that emerge during infancy track through childhood and have lasting effects on the development of food preferences and control of intake later in life (Golley et al., 2013; North \& Emmett, 2000; Northstone \& Emmett, 2005; Skinner, Carruth, Bounds, Ziegler, \& Reidy, 2002). For example, children who consume sugar-sweetened beverages (SSBs) during infancy are more likely to consume them at age 6 years whereas not consuming fruits and vegetables (F\&V) makes children less likely to consume them later on (Park, Pan, Sherry, \& Li, 2014). One possible, yet understudied, determinant of infant diet is maternal diet (Howard, Mallan, Byrne, Magarey, \& Daniels, 2012; Wen, Simpson, Rissel, \& Baur, 2013). Mothers are typically responsible for purchasing food, preparing meals, and feeding their children. A mother's preference for and consumption of certain foods could impact whether or not they are offered to their children, which for older children has been shown to influence not only their dietary preferences, but also their weight (Fisher \& Birch, 1995; Howard et al., 2012; Papas, Hurley, Quigg, Oberlander, \& Black, 2009; Robinson et al., 2007; Saavedra, Deming, Dattilo, \& Reidy, 2013).

For many women, diet quality is suboptimal, particularly in the postpartum period (Durham, Lovelady, Brouwer, Krause, \& Ostbye, 2011; Fowles \& Walker, 2006; George, Hanss-Nuss, Milani, \& Freeland-Graves, 2005; Wiltheiss et al., 2013). For example, $92.7 \%$ of adult females aged 19-30 do not meet the minimum recommendation for fruit, $94.1 \%$ for vegetables and $99.8 \%$ for whole grains (KrebsSmith, Guenther, Subar, Kirkpatrick, \& Dodd, 2010). Nearly all children aged $2-3$ years (99.4\%) and $94.4 \%$ of adult females aged $19-30$ years exceed recommendations for solid fats, and $98.3 \%$ and $85.0 \%$ exceed 
recommendations for added sugars, respectively (Krebs-Smith et al., 2010). Increasing evidence suggests that consuming obesogenic foods, or energy dense/nutrient-poor foods, such as desserts, salty snacks, and SSBs in place of nutrient- and fibre-rich foods such as F\&V and whole grains contributes to unhealthy eating patterns and weight gain (Houchins et al., 2012; Leahy, Birch, \& Rolls, 2008; Rolls, Ello-Martin, \& Tohill, 2004).

Understanding the influence that maternal diet has on infant diet may be particularly important among NHB families, owing to their different feeding practices compared to other races/ethnicities, such as greater likelihood for early introduction of inappropriate foods (Thompson \& Bentley, 2013) and breastfeeding rates that lag far behind that of white and Hispanic women (Centers for Disease, C., \& Prevention, 2010). Yet few studies have been conducted among dyads from this important racial/ethnic group. Given the importance of early learning on the development of food preferences and the prevalence of obesogenic diets, a need for longitudinal studies focused on infant consumption in NHB families exists. The purpose of this study is to (a) explore maternal and infant consumption of key food groups, including those associated with an obesogenic diet, from 6 to 18 months postpartum in a low-income, NHB population, (b) identify predictors of maternal and infant intake, and (c) determine associations between maternal and infant consumption of key food groups so that results can be used to guide interventions aimed at influencing intake during the first 2 years of life.

\section{I PARTICIPANTS AND METHODS}

Data come from the Infant Care, Feeding, and Risk of Obesity Project (Infant Care), a longitudinal, observational cohort study of first-time, NHB mothers aged 18-35 years who were recruited through the North Carolina Special Supplemental Nutrition Program for Women, Infants, and Children (WIC) (Laraia, Borja, \& Bentley, 2009; Sacco, Bentley, Carby-Shields, Borja, \& Goldman, 2007; Thompson, Adair, \& Bentley, 2013; Thompson \& Bentley, 2013; Wasser et al., 2011; Wasser et al., 2013). WIC is a federal assistance program that provides health care and nutrition for low-income pregnant and/or breastfeeding women and infants and children under 5. Data collection began in November 2003 and was completed in October 2007. Two hundred seventeen dyads were recruited. Mother-infant dyads were followed with in-home visits when infants were 3, 6, 9, 12, and 18 months of age. At each home visit, various maternal, infant, and household characteristics were assessed through intervieweradministered questionnaires. Infants who were $\leq 35$ weeks gestation, $<2500$ or $\geq 4500$ grams in birth weight, had chronic or congenital illness, were receiving medical treatment that interfered with dietary intake, growth, or development (e.g., Down's syndrome, cerebral palsy, epilepsy, diagnosed mental retardation, cleft lip, or palate), or presented with failure-to-thrive were excluded from the study.

The analytic sample includes 179 unique mother-infant dyads with dietary intake data from at least one of the home visits at months $6,9,12$, and 18. The protocol was approved by the Institutional Review Board at the University of North Carolina at Chapel Hill.

\section{Key messages}

- Dietary guidelines are needed for infants and toddlers. Currently, the DGAs begin at age 2; an initiative is under way to include these populations in future DGAs, which, as our study demonstrates, is necessary.

- Infancy is an opportune time to intervene, for that is when food preferences and lifelong diet habits begin to form. The impact maternal dietary behaviours can have on infants should not be ignored given the implications role modelling can have on a child's dietary habits and food preferences.

- Programs that target adoption of healthy eating behaviours in mothers may prove beneficial for young children's eating behaviours and subsequent obesity risk.

\section{1 | Dietary intake}

During each home visit, maternal and infant dietary intakes were assessed with computerized 24-hr dietary recalls (24HDRs) administered by trained study personnel using the Nutrient Data System for Research (version 2005; Nutrition Coordinating Center, University of Minnesota, Minneapolis, MN). For infants, to improve estimates of usual food intakes, an additional 24HDR was collected via telephone on a random, nonconsecutive day within 2 weeks of the home visit (Thompson \& Subar, 2013). Mothers were instructed in advance to obtain information about any foods and beverages consumed by the infant while not in her care. Food models and pictures were used to aid in the estimation of portion sizes. One 24HDR was used for mothers, and an average of two 24HDRs were used for infants from each visit.

Key food groups were similar to those used in the Feeding Infants and Toddlers study (FITS) and included low energy-dense foods as well as foods higher in energy density (Briefel et al., 2010). Low energydense food groups were defined according to the 2015-2020 Dietary Guidelines for Americans (DGAs): fruits (including 100\% fruit juice), vegetables (excluding fried vegetables), whole grains, and lean protein foods (meat, poultry, seafood, eggs, soy products, and nuts) (U.S. Department of Health and Human Services and U.S. Department of Agriculture, 2015). Energy-dense food groups included SSBs, salty snacks, desserts and sweets, and fried vegetables, which include French fries, hash browns, and onion rings; according to the American Academy of Pediatrics, these foods are considered inappropriate for infants and toddlers and should not be consumed (American Academy of Pediatrics, 2014). Mothers and infants were defined as "consumers" of each food group (yes/no) if consumption of any amount occurred at least once in the food record.

\section{2 | Predictor variables}

Predictors of intake were drawn from the literature and include factors previously associated with maternal and infant diet: maternal education, age, body mass index (BMI), marital status, employment, 
depression, living in a single-headed household, breastfeeding and infant weight-for-height and sex (George et al., 2005; Hendricks, Briefel, Novak, \& Ziegler, 2006; Smithers et al., 2012; Wiltheiss et al., 2013). Depression was measured using the Center for Epidemiological Studies Depression Scale (Radloff, 1977). For breastfeeding status, mothers were asked at each visit whether they were still breastfeeding. Maternal weight and height were measured by a trained research assistant at a subset of visits (3, 6, and 18 months), and BMI was calculated for each individual, weight $(\mathrm{kg}) / \mathrm{height}(\mathrm{m})^{2}$. Weight status was categorized based on international classification guidelines: underweight $/$ normal $=\mathrm{BMI}<25$; overweight $=\mathrm{BMI} 25-29.9$; and obese $=\mathrm{BMI} \geq 30.0$. Infant anthropometrics were measured at each home visit. Weight-for-length $z$-scores were calculated using the CDC/NCHS 2000 growth reference (Ogden et al., 2002).

\section{3 | Statistical analysis}

Sample characteristics at each time point $(6,9,12$, and 18 months) are described as frequencies for categorical variables and means and standard deviations for continuous variables. Data are presented as the proportion consuming any amount of a food group at each time point.
Polychoric correlation matrices were used to test for collinearity among predictors. Marital status was highly correlated with education and single-headed households ( $r$ o $\geq 0.7$ ) and was therefore dropped as a predictor. We assessed the bivariate relationship of demographic and household characteristics with infant and maternal intake separately for each food group.

We used random intercept logistic regression models to assess how infant consumption of foods from each food group related to maternal consumption of that same food group, adjusting for demographic and household characteristics shown to be significant predictors in bivariate analyses, plus a variable representing study visit (time). All tests were two-sided, and $p$ values $<0.05$ were regarded as statistically significant. Due to correlations between outcome variables, correction for multiple testing using the Bonferroni method (which assumes totally independent tests and variables) was not applied. To account for missingness in the demographic and household predictor values, we imputed using the last observation carried forward method. To address the potential for selection bias, differences in baseline characteristics between those who were present and those who were absent at each visit were assessed. All analyses were conducted using Stata 14 (StataCorp, College Station, TX).

TABLE 1 Demographic characteristics of mothers and infants participating in the Infant Care, Feeding, and Risk of Obesity study

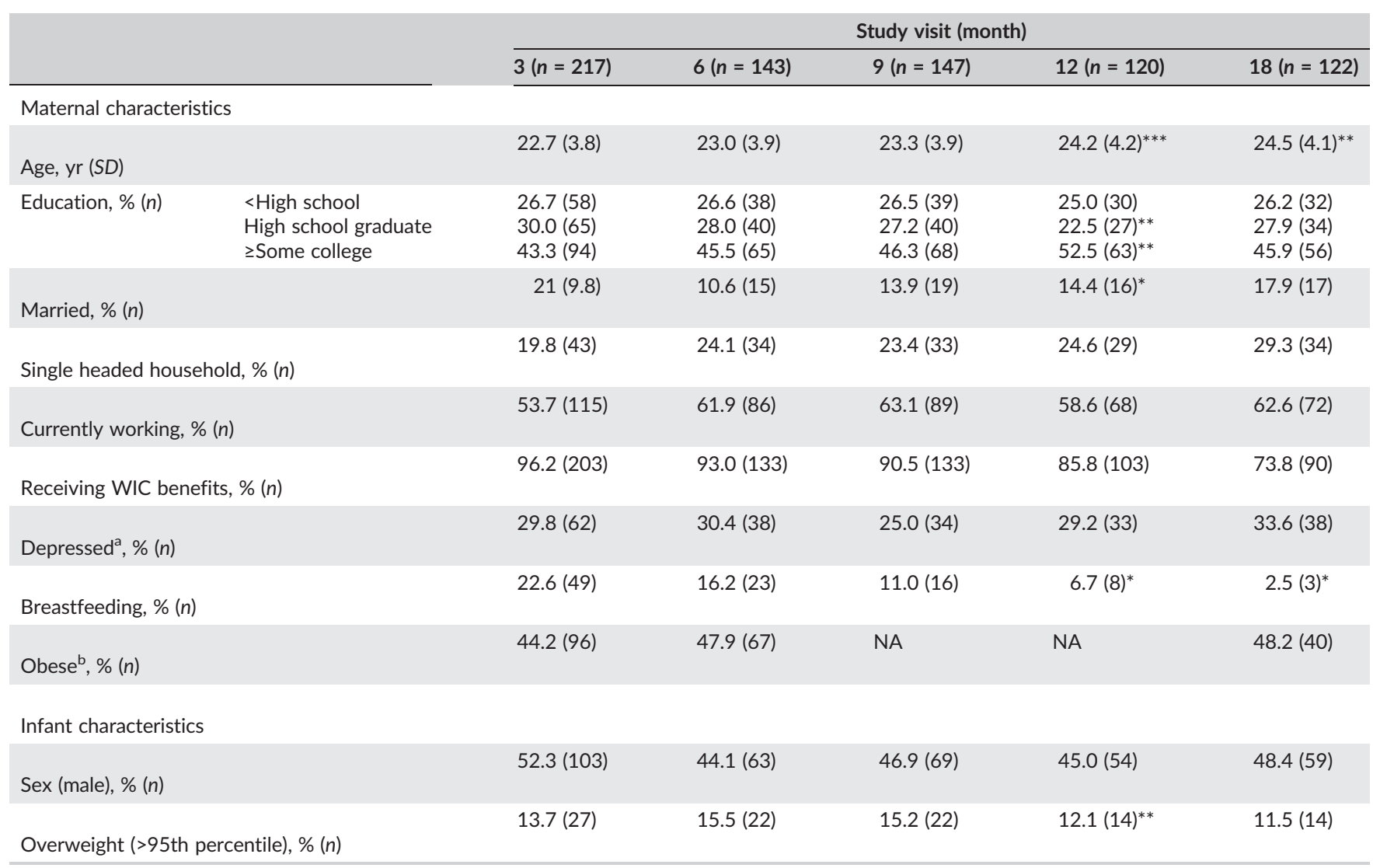

Significantly different at baseline at

${ }^{*} p<.05$.

${ }^{* *} p<.01$.

${ }^{* * *} p<.001$.

${ }^{\text {a }}$ Measured using the Center for Epidemiological Studies Depression Scale with a score of $\geq 16$ indicating depressive symptoms.

${ }^{b}$ Weight status was not measured at the 9- and 12-month visits. 


\section{3 | RESULTS}

Dietary recalls were collected from 143 mothers-infant dyads at month 6 (65.9\%), 147 at month 9 (67.7\%), 120 at month 12 (55.3\%), and 122 at month 18 (56.2\%; see Table 1$)$. In total, there were 179 unique mother-infant dyads across all time points. There was a high prevalence of obesity within this sample of young, first-time NHB mothers. Most mothers were receiving benefits from the North Carolina Supplemental Nutrition Program for Women, Infants, and Children (WIC), and many were employed. Few mothers were breastfeeding at 6 months, and rates significantly decreased over time. Differences among those who had complete dietary recalls versus those who did not at each time point revealed few significant differences (see Table 1). Mothers with dietary recalls at 12 months were more likely to be older, married, breastfeeding and have a higher level of education and less likely to have an overweight infant at baseline. Those with dietary recalls at 18 months were more likely to be breastfeeding at baseline.

Across study visits, most mothers reported consuming vegetables and lean protein foods, and less than half consumed fruit, juice, and whole grains on a given day (see Figure 1). Most mothers reported consuming SSBs, and at least a quarter of the mothers consumed desserts and sweets, fried vegetables, and salty snacks on a given day. Over time, the percentage of children consuming each of the food groups increased with nearly all children consuming fruit, vegetables, lean protein foods, and juice at the 18-month visit. At the 12-month visit, at least half the children consumed SSBs, desserts and sweets, and salty snacks. At the 18-month visit, more than half the children consumed fried vegetables, SSBs, and salty snacks and over $80 \%$ consumed desserts and sweets. A smaller proportion of fruit, vegetables, and juice came from baby foods across study visits. Compared to mothers, a higher percentage of infants consumed fruit, whole grains, juice, and desserts and sweets.

The unadjusted results from the bivariate analyses revealed various significant predictors of intake for both mothers and their infants, see Tables 2A and 2B. Higher maternal age (years), education level, and breastfeeding were associated with more favourable dietary intake in mothers and their children, and the presence of depressive symptoms was associated with less favourable intake (data not shown); maternal obesity was associated with infant intake. Therefore, maternal age, education, breastfeeding, depression, and obesity were included as covariates in the random intercept logistics regression models.
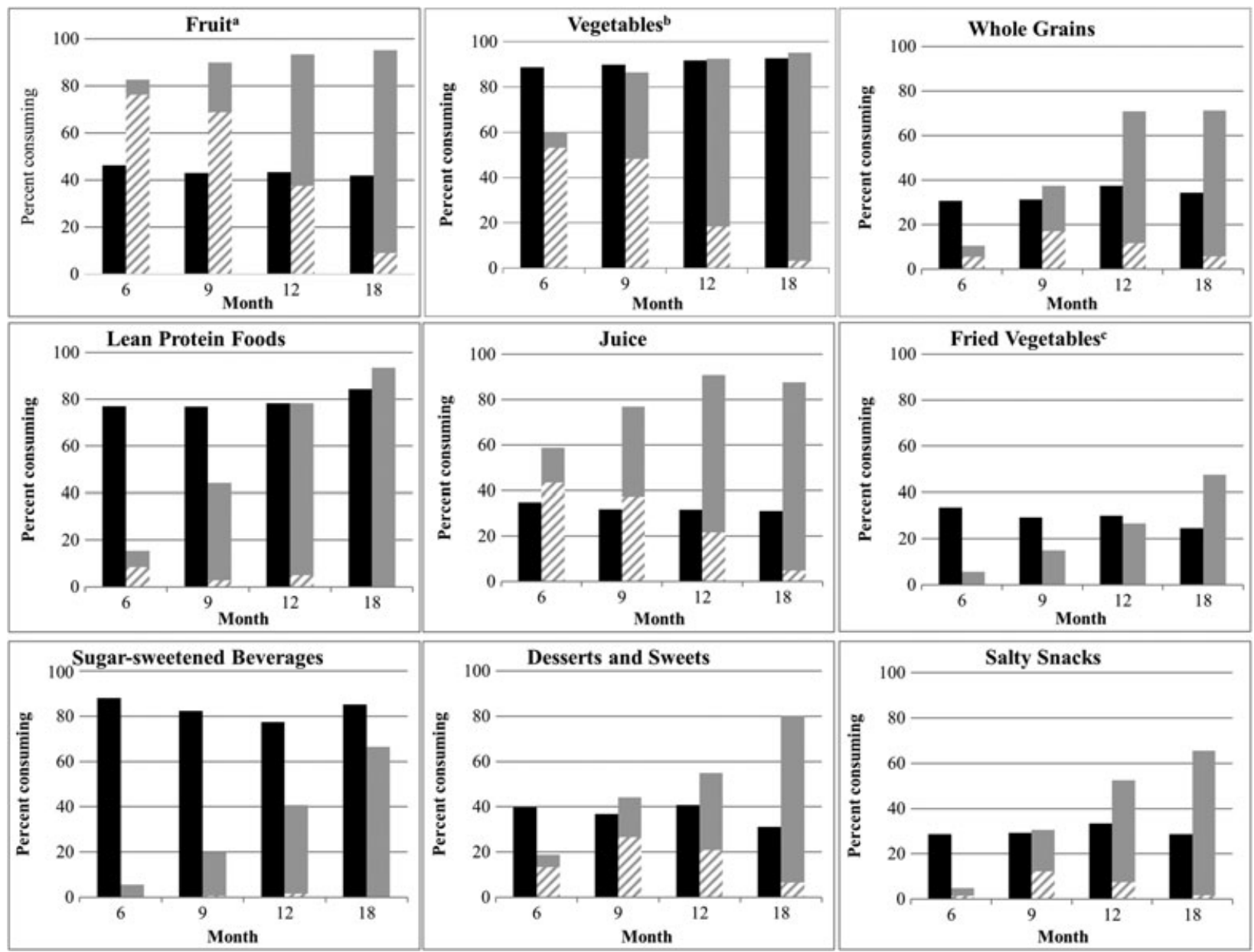

FIGURE 1 Percent consuming key food groups among mothers and infants aged 6 to 18 months participating in the Infant Care, Feeding, and Risk of Obesity study. Legend: Mom, Infant, $>$ Proportion of foods consumed by infants that were baby foods. ${ }^{\mathrm{a}}$ All fruit, including whole fruit and juice. ${ }^{b}$ All vegetables, including whole and juice, excluding fried vegetables. Includes breaded and fried vegetables such as French fries, hash browns, and onion rings 


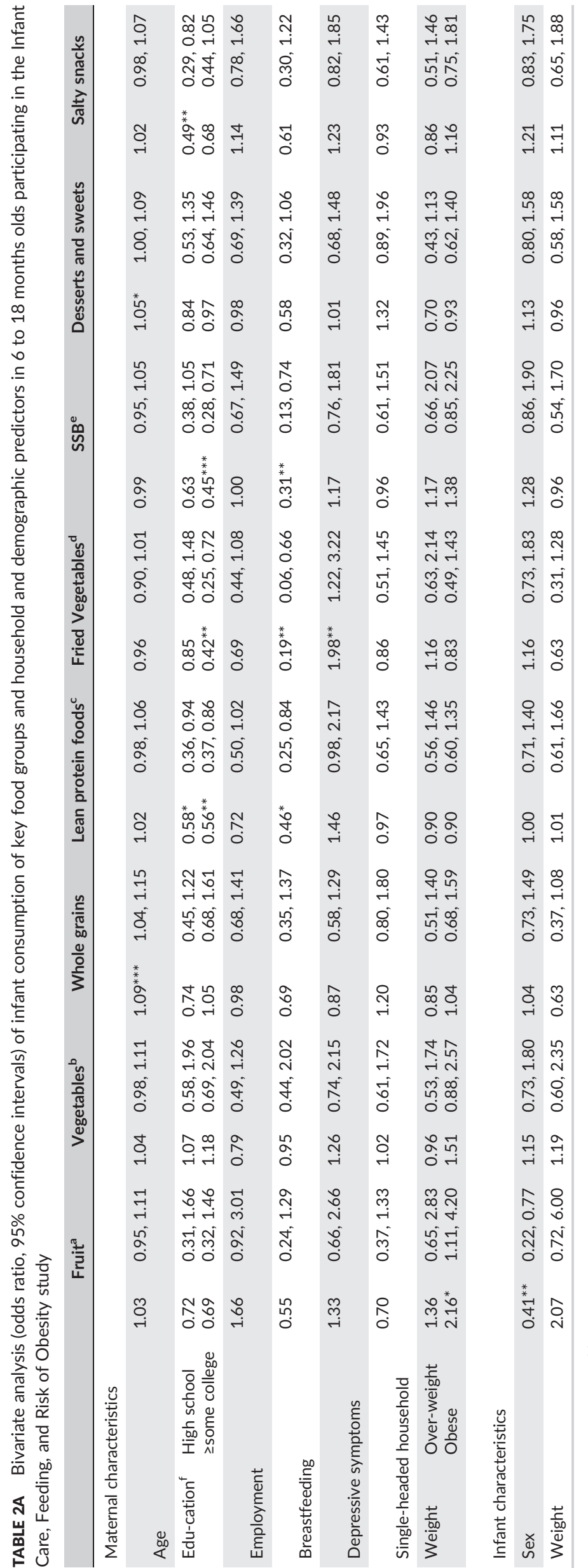

กิ

న్

تี

里

然

$\stackrel{9}{7} \stackrel{\circ}{\circ}$

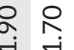

足

ำ

ֻ

एँ

赵

ํ.

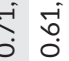

훅

守

角

శై

空

rio

ن.

茎产

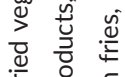

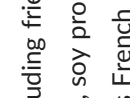

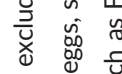

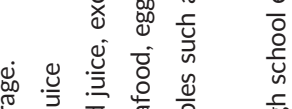

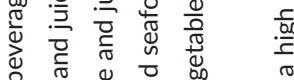

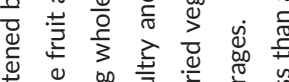

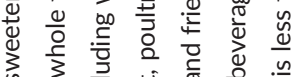

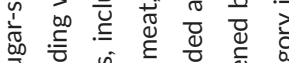

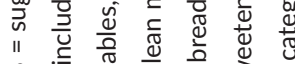

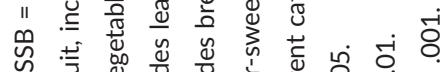

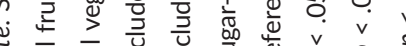

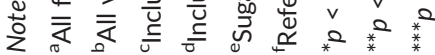



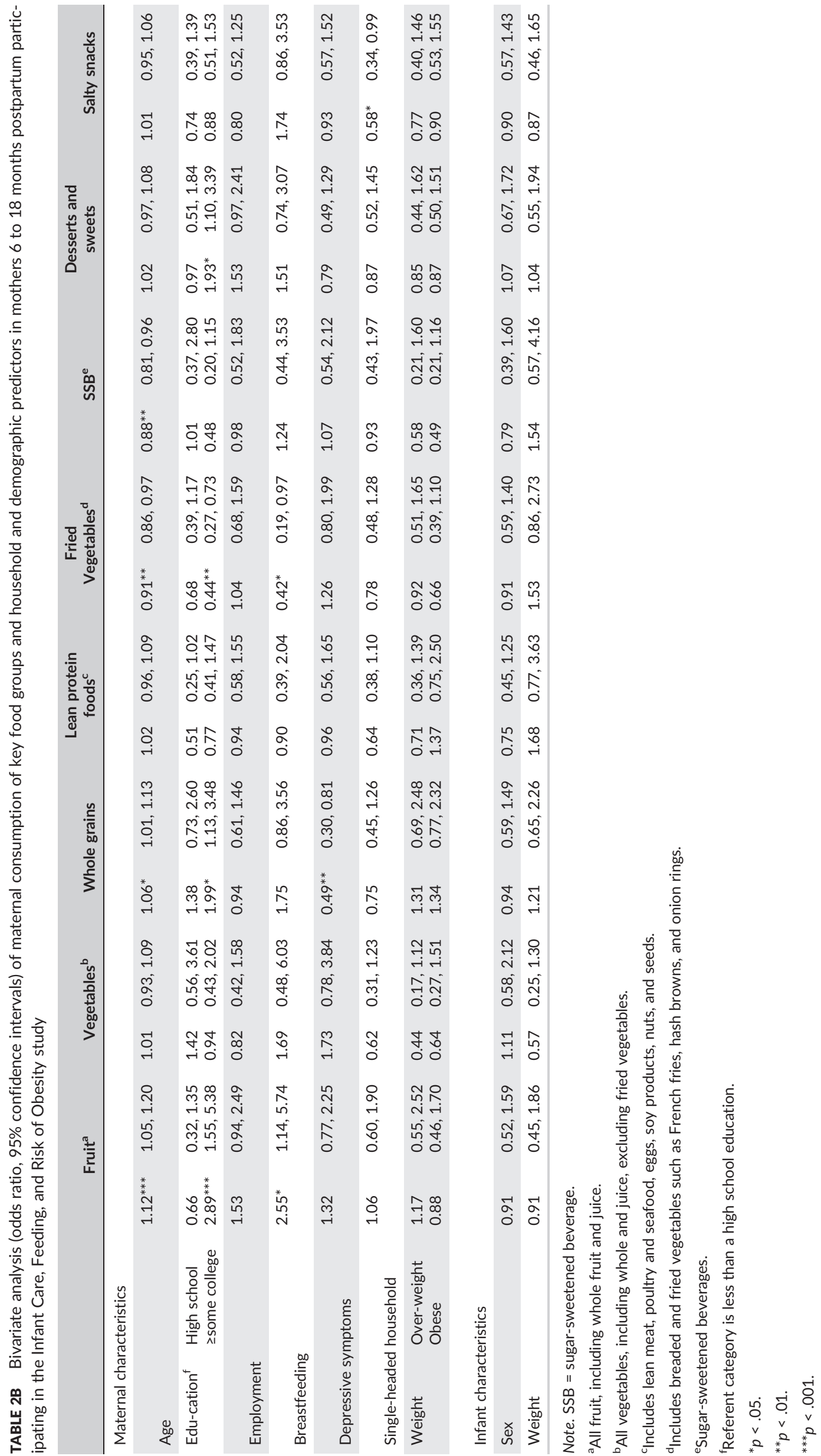

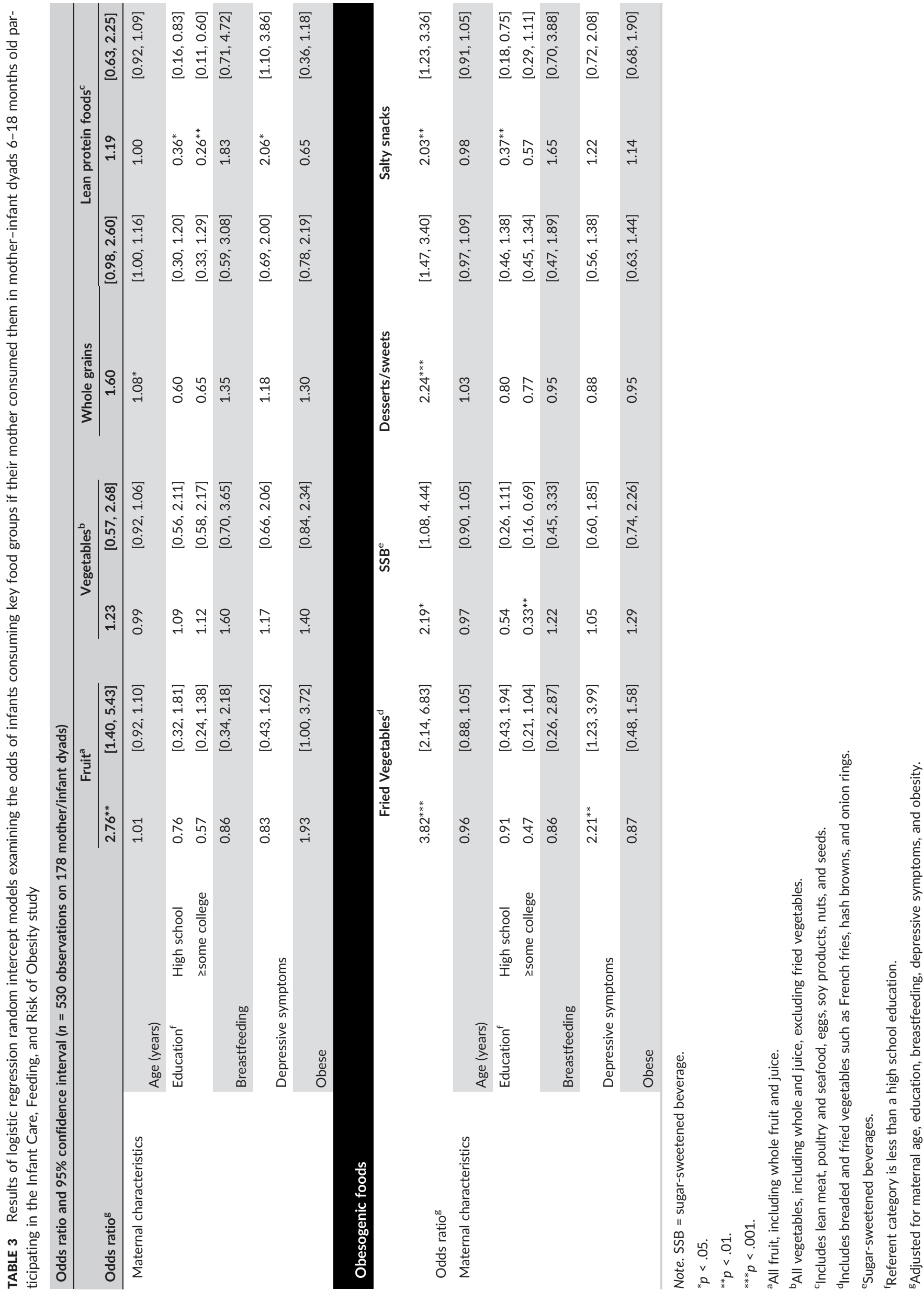
The results from the adjusted random intercept logistics regression models revealed that if mothers consume obesogenic foods, their infants are more likely to do so. Infants were at least 2 times as likely to consume SSBs, desserts, sweets, and salty snacks if their mother consumed them (see Table 3 ) and more than 3 times as likely to consume fried vegetables. Infants were more likely to consume fruit if their mother consumed it, though the association was attenuated when juice was excluded (data not shown). There were no significant associations of maternal intake of vegetables, whole grains, or lean protein foods with infant intake of these foods. Infants were more likely to consume whole grains if their mother was older. Infants were more likely to consume lean protein foods and fried vegetables if their mother exhibited depressive symptoms. Infants were less likely to consume lean protein foods, SSBs, and salty snacks if their mother had a higher education level. There were no significant associations among infants of mothers breastfeeding for any of the food groups.

\section{4 | DISCUSSION}

This study explores maternal and infant consumption of key food groups from 6 to 18 months postpartum and examines associations between maternal consumption of such foods and infant consumption. Understanding the link between diets of mothers and their young children is important as it broadens our understanding of potential pathways for influencing early life nutrition that can help to refine nutrition-focused interventions and improve dietary intakes of these young children. This study demonstrates that NHB infants are consuming obesogenic foods such as SSBs as early as 6 months and continuing to do so through infancy. Our results were similar to those in a study of a nationally representative sample of infants aged 0 to 48 months in which $43 \%$ of 9-11 months olds consumed some type of dessert, sweet, or SSB at least once in a day, and this percentage increased to $72 \%$ at $12-23$ months (Saavedra et al., 2013; Siega-Riz et al., 2010).

Despite early consumption of obesogenic foods, infant diets may be better than those of their mothers given the higher proportion consuming low-energy dense foods on a given day, a finding supported elsewhere (Hoerr, Dersch, Vandenbilt, Luster, \& VonEye, 1998; Lee, Hoerr, \& Schiffman, 2005). For example, in our sample, less than half of mothers consumed fruit and whole grains on a given day and although many consumed vegetables, the average median serving was 1.25 , which is a quarter of the recommended daily amount. Furthermore, most women consumed SSBs and many consumed desserts and sweets. These results are not surprising; other research shows that for many women diet quality is suboptimal, particularly in the postpartum period (Durham et al., 2011; Fowles \& Walker, 2006; George et al., 2005; Wiltheiss et al., 2013). Comparatively, nearly all children consumed vegetables on a given day and approximately twice the number of children consumed fruit and whole grains by 18 months compared to the percent of mothers consuming them. However, by 18 months, a higher number of children also consumed fried vegetables, desserts, and salty snacks compared to mothers. Although surprising, the consumption of obesogenic foods throughout infancy is not unique to this population. National survey data from the FITS shows that potentially obesogenic diets emerge early with infants fed SSBs and energy dense foods such as desserts and candy and a substantial proportion do not consume any fruits or vegetables in a given day (Fox, Reidy, Novak, \& Ziegler, 2006; Siega-Riz et al., 2010).

In assessing predictors of infant and maternal intake, it is evident that certain demographic and household characteristics can have an impact on what children and their mothers eat, particularly maternal age, education, and breastfeeding. Higher maternal education levels and age are generally associated with a more favourable eating pattern in infants (Brekke, van Odijk, \& Ludvigsson, 2007; Northstone \& Emmett, 2005; Robinson et al., 2007; Smithers et al., 2012; Svensson et al., 2016). In our study, a higher education level was associated with infants being less likely to consume obesogenic foods. Mothers with higher education appear to know or follow recommendations for feeding healthier foods to their infants; however, they do not appear to apply this information to their own diet.

Our study demonstrates that infant consumption is strongly associated with that of their mother. Infants were significantly more likely to consume key food groups if their mother consumed them, particularly obesogenic foods. Interestingly, infants of mothers exhibiting depressive symptoms were more likely to consume lean protein foods and fried vegetables if their mother was consuming them. Although most lean protein foods are considered healthy choices, the most commonly consumed lean protein food among mothers in this study were chicken drumsticks with the skin eaten (data not shown), which have higher calories, fat, and saturated fat compared to other forms of chicken. In addition, the most commonly consumed fried vegetables were fast food French fries. Evidence is sparse, but some studies have linked maternal mental health to dietary patterns in older children (Ystrom, Niegel, \& Vollrath, 2009). During times of stress, mothers may be more likely to feed their children, and themselves, unhealthy foods, perhaps for ease in caregiving, leading to convenient, and often unhealthy, food choices (Hurley, Black, Merry, \& Caulfield, 2015; Ystrom et al., 2009).

The home environment is key to understanding the development of children's diet and food preferences, for young children ages 2-6 years consume $71 \%$ of their daily energy intake at home (Poti \& Popkin, 2011). As infants make the significant dietary transition from a milk-based diet to foods indicative of their caregiver's diet, they learn what, when, and how much to eat from those around them. Although few studies exist among infants, studies among mothers of preschoolage children suggest that maternal influence on children's food intake occurs primarily through role modelling and food availability in the home (Anzman, Rollins, \& Birch, 2010; Hart, Raynor, Jelalian, \& Drotar, 2010; Wang, Beydoun, Li, Liu, \& Moreno, 2011). Role modelling healthy food choices (e.g., F\&V and foods low in added sugar and fat) is an important component to shaping healthy diets in children. Maternal preference for obesogenic foods can send conflicting messages, such as when asking a child to eat $F \& V$ that she herself is not consuming. However, few interventions aim to change maternal diet directly (Havas et al., 1998; Lioret et al., 2012; Ostbye et al., 2012). What our study shows is that an important and often overlooked path for intervening on infant diet is through maternal diet as it can influence the types of complementary foods available in the home and subsequently offered. 
A major strength of this study is that it consisted of longitudinal data on matched mother-infant dyads. To our knowledge, it is the first study to focus on the consumption of key food groups in infants and toddlers among a sample of NHB, low-income mothers, a population often not well represented in national surveys. Although our focus is on a unique and understudied population, these findings should be considered with caution in light of some limitations. First, given the focus on a particular population, generalizability of findings may be limited. The women sampled were all NHB first-time mothers, recruited through WIC; future studies should include a larger, more heterogeneous sample. However, data were collected prior to the reauthorization of WIC food packages, which now include vouchers for fresh F\&V, an important policy change that could influence F\&V intake, warranting future research in this population. Underreporting of intake is also concern, given the large percentage of overweight or obese women in our sample (Braam, Ocke, Bueno-de-Mesquita, \& Seidell, 1998; Johansson, Wikman, Ahren, Hallmans, \& Johansson, 2001). However, studies indicate that foods perceived to be most healthy are the least likely to be omitted (Becker \& Welten, 2001; Hirvonen, Mannisto, Roos, \& Pietinen, 1997). Thus, considering the reported intakes as conservative estimates only strengthens the need to intervene, for intake of vegetables and whole grains was low, whereas that of obesogenic food groups was high. The use of a single 24HDR for assessing maternal intake could bias our estimates of episodically consumed foods due to the inability to classify an individual as a true nonconsumer. However, aggregating foods into key food groups can minimize this risk; furthermore, one-day estimates from 24HDR have been used in other studies such as the FITS, a dietary intake survey of parents and caregivers of young children (Briefel, Ziegler, Novak, \& Ponza, 2006). Although we use only one 24HDR at each time point, sensitivity analyses demonstrated a lack of change in consumption patterns over time (data not shown); therefore, we chose to use one recall from each time point in order to match on infant recalls. In measuring the association between infant and maternal intake, it is important to note that we are not measuring concordance of intake, for at least one of the two 24HDR for infants was collected on a different day than the mother's. Given that approximately $60 \%$ of mothers were employed at each time point, infants are not likely to be eating every meal with their mother. The significant associations found among infant and maternal intake are likely due to both the food environment, which is largely shaped by the mother, and role modelling. Finally, as with many cohort studies, our results are subject to selection bias due to loss to follow up, especially given mothers who did not complete the study exhibited characteristics often associated with poor diets. Using the last observation carried forward method for predictors that are expected to change, such as weight and depression, could impact our findings by inducing bias as well as understating variability. However, sensitivity analyses using complete case data revealed no significant differences in results.

Future research should focus on developing effective interventions that support mothers in adopting healthy eating behaviours for themselves and their children throughout the postpartum period. Our research shows that mothers may have adequate knowledge of what constitutes a healthy diet, and thus feed their children in that way, but adequate nutrition knowledge may not be a sufficient factor in influencing their own intake (Worsley, 2002). Given the link between maternal and infant consumption, particularly for obesogenic foods, and the importance of role modelling healthy food choices as children age and their acceptance of solid foods broadens, targeting maternal diet could be an effective strategy for preventing early life obesity.

\section{ACKNOWLEDGMENTS}

Special thanks to Dr Phil Bardsley of the Carolina Population Center for assistance in analysis.

\section{CONFLICTS OF INTEREST}

The authors declare that they have no conflicts of interests.

\section{CONTRIBUTIONS}

MCK conceptualized and designed the study, acquired the data, analyzed and interpreted the data, drafted the initial manuscript, and approved the final manuscript as submitted. HMW assisted with the conceptualization and design of the study, revised the manuscript, and approved the final manuscript as submitted. LSA assisted with the conceptualization and design of the study, revised the manuscript, and approved the final manuscript as submitted. ALT assisted with the conceptualization and design of the study, revised the manuscript, and approved the final manuscript as submitted. AMS-R assisted with the conceptualization and design of the study, revised the manuscript, and approved the final manuscript as submitted. CMS assisted with the conceptualization and design of the study, revised the manuscript, and approved the final manuscript as submitted. MEB conceptualized and designed the study, revised the manuscript, and approved the final manuscript as submitted.

\section{REFERENCES}

Anzman, S. L., Rollins, B. Y., \& Birch, L. L. (2010). Parental influence on children's early eating environments and obesity risk: Implications for prevention. International Journal of Obesity, 34, 1116-1124 England.

Baird, J., Fisher, D., Lucas, P., Kleijnen, J., Roberts, H., \& Law, C. (2005). Being big or growing fast: Systematic review of size and growth in infancy and later obesity. BMJ (Clinical research ed.), 331, 929.

Becker, W., \& Welten, D. (2001). Under-reporting in dietary surveys-Implications for development of food-based dietary guidelines. Public Health Nutrition, 4, 683-687.

Braam, L. A., Ocke, M. C., Bueno-de-Mesquita, H. B., \& Seidell, J. C. (1998). Determinants of obesity-related underreporting of energy intake. American Journal of Epidemiology, 147, 1081-1086.

Brekke, H. K., van Odijk, J., \& Ludvigsson, J. (2007). Predictors and dietary consequences of frequent intake of high-sugar, low-nutrient foods in 1 -year-old children participating in the ABIS study. The British Journal of Nutrition, 97, 176-181.

Briefel, R., Ziegler, P., Novak, T., \& Ponza, M. (2006). Feeding Infants and Toddlers Study: Characteristics and usual nutrient intake of Hispanic and non-Hispanic infants and toddlers. Journal of the American Dietetic Association, 106, S84-S95.

Briefel, R. R., Kalb, L. M., Condon, E., Deming, D. M., Clusen, N. A., Fox, M. K., ... Reidy, K. C. (2010). The feeding infants and toddlers study 2008 : study design and methods. Journal of the American Dietetic Association, 110(12 Suppl), S16-S26.

Centers for Disease, C., \& Prevention. (2010). Racial and ethnic differences in breastfeeding initiation and duration, by state-National Immunization Survey, United States, 2004-2008. MMWR.Morbidity and mortality weekly report, 59, 327-334. 
Dalenius, K., Borland, E., Smith, B., Polhamus, B., \& Grummer-Strawn, L. (2012). Pediatric nutrition surveillance report. Retrieved from Atlanta:

Durham, H. A., Lovelady, C. A., Brouwer, R. J., Krause, K. M., \& Ostbye, T. (2011). Comparison of dietary intake of overweight postpartum mothers practicing breastfeeding or formula feeding. Journal of the American Dietetic Association, 111, 67-74.

Fisher, J. O., \& Birch, L. L. (1995). Fat preferences and fat consumption of 3to 5 -year-old children are related to parental adiposity. Journal of the American Dietetic Association, 95, 759-764.

Fowles, E. R., \& Walker, L. O. (2006). Correlates of dietary quality and weight retention in postpartum women. Journal of Community Health Nursing, 23, 183-197.

Fox, M. K., Reidy, K., Novak, T., \& Ziegler, P. (2006). Sources of energy and nutrients in the diets of infants and toddlers. Journal of the American Dietetic Association, 106(1 Suppl 1), S28-S42.

Freedman, D. S. (2011). CDC Health Disparities and Inequalities Report -United States, 2011: Obesity-United States, 1988-2008. MMWR, $60,73$.

George, G. C., Hanss-Nuss, H., Milani, T. J., \& Freeland-Graves, J. H. (2005). Food choices of low-income women during pregnancy and postpartum. Journal of the American Dietetic Association, 105, 899-907.

Golley, R. K., Smithers, L. G., Mittinty, M. N., Emmett, P., Northstone, K., \& Lynch, J. W. (2013). Diet quality of U.K. infants is associated with dietary, adiposity, cardiovascular, and cognitive outcomes measured at 7-8 years of age. The Journal of Nutrition, 143, 1611-1617.

Hart, C. N., Raynor, H. A., Jelalian, E., \& Drotar, D. (2010). The association of maternal food intake and infants' and toddlers' food intake. Child: Care, Health and Development, 36, 396-403.

Havas, S., Anliker, J., Damron, D., Langenberg, P., Ballesteros, M., \& Feldman, R. (1998). Final results of the Maryland WIC 5-A-Day promotion program. American Journal of Public Health, 88, 1161-1167.

Hendricks, K., Briefel, R., Novak, T., \& Ziegler, P. (2006). Maternal and child characteristics associated with infant and toddler feeding practices. Journal of the American Dietetic Association, 106, S135-S148.

Hirvonen, T., Mannisto, S., Roos, E., \& Pietinen, P. (1997). Increasing prevalence of underreporting does not necessarily distort dietary surveys. European Journal of Clinical Nutrition, 51, 297-301.

Hoerr, S., Dersch, H., Vandenbilt, M., Luster, T., \& VonEye, A. (1998). Fruit and vegetable consumption predicts nutrient adequacy for young mothers and their preschool children. FASEB Journal, 12.

Houchins, J. A., Burgess, J. R., Campbell, W. W., Daniel, J. R., Ferruzzi, M. G. McCabe, G. P., \& Mattes, R. D. (2012). Beverage vs. solid fruits and vegetables: Effects on energy intake and body weight. Obesity (Silver Spring, Md.), 20, 1844-1850.

Howard, A. J., Mallan, K. M., Byrne, R., Magarey, A., \& Daniels, L. A. (2012). Toddlers' food preferences. The impact of novel food exposure, maternal preferences and food neophobia. Appetite, 59, 818-825.

Hurley, K. M., Black, M. M., Merry, B. C., \& Caulfield, L. E. (2015). Maternal mental health and infant dietary patterns in a statewide sample of Maryland WIC participants. Maternal \& Child Nutrition, 11, 229-239.

Johansson, G., Wikman, A., Ahren, A. M., Hallmans, G., \& Johansson, I. (2001). Underreporting of energy intake in repeated 24-hour recalls related to gender, age, weight status, day of interview, educational level, reported food intake, smoking habits and area of living. Public Health Nutrition, 4, 919-927.

Krebs-Smith, S. M., Guenther, P. M., Subar, A. F., Kirkpatrick, S. I., \& Dodd, K. W. (2010). Americans do not meet federal dietary recommendations. The Journal of Nutrition, 140, 1832-1838.

Laraia, B. A., Borja, J. B., \& Bentley, M. E. (2009). Grandmothers, fathers, and depressive symptoms are associated with food insecurity among low-income first-time African-American mothers in North Carolina. Journal of the American Dietetic Association, 109, 1042-1047.

Leahy, K. E., Birch, L. L., \& Rolls, B. J. (2008). Reducing the energy density of multiple meals decreases the energy intake of preschool-age children. The American Journal of Clinical Nutrition, 88, 1459-1468.
Lee, S. Y., Hoerr, S. L., \& Schiffman, R. F. (2005). Screening for infants' and toddlers' dietary quality through maternal diet. MCN.The American journal of maternal child nursing, 30, 60-66.

Lioret, S., Campbell, K. J., Crawford, D., Spence, A. C., Hesketh, K., \& McNaughton, S. A. (2012). A parent focused child obesity prevention intervention improves some mother obesity risk behaviors: The Melbourne inFANT program. The international journal of behavioral nutrition and physical activity, 9, 100-5868-5869-5100.

Nader, P. R., O'Brien, M., Houts, R., Bradley, R., Belsky, J., Crosnoe, R., ... Human Development Early Child Care Research, N. (2006). Identifying risk for obesity in early childhood. Pediatrics, 118, e594-e601.

North, K., \& Emmett, P. (2000). Multivariate analysis of diet among threeyear-old children and associations with socio-demographic characteristics. The Avon Longitudinal Study of Pregnancy and Childhood (ALSPAC) Study Team. European Journal of Clinical Nutrition, 54, 73-80.

Northstone, K., \& Emmett, P. (2005). Multivariate analysis of diet in children at four and seven years of age and associations with socio-demographic characteristics. European Journal of Clinical Nutrition, 59, 751-760.

Ogden, C. L., Carroll, M. D., Kit, B. K., \& Flegal, K. M. (2014). Prevalence of childhood and adult obesity in the United States, 2011-2012. JAMA : The Journal of the American Medical Association, 311, 806-814.

Ogden, C. L., Kuczmarski, R. J., Flegal, K. M., Mei, Z., Guo, S., Wei, R., ... Johnson, C. L. (2002). Centers for Disease Control and Prevention 2000 growth charts for the United States: Improvements to the 1977 National Center for Health Statistics version. Pediatrics, 109, 45-60.

Ostbye, T., Krause, K. M., Stroo, M., Lovelady, C. A., Evenson, K. R., Peterson, B. L., ... Zucker, N. L. (2012). Parent-focused change to prevent obesity in preschoolers: Results from the KAN-DO study. Preventive Medicine, 55, 188-195.

Papas, M. A., Hurley, K. M., Quigg, A. M., Oberlander, S. E., \& Black, M. M. (2009). Low-income, African American adolescent mothers and their toddlers exhibit similar dietary variety patterns. Journal of Nutrition Education and Behavior, 41, 87-94.

Park, S., Pan, L., Sherry, B., \& Li, R. (2014). The association of sugar-sweetened beverage intake during infancy with sugar-sweetened beverage intake at 6 years of age. Pediatrics, 134(Suppl 1), S56-S62.

Poti, J. M., \& Popkin, B. M. (2011). Trends in energy intake among US children by eating location and food source, 1977-2006. Journal of the American Dietetic Association, 111, 1156-1164.

Radloff, L. S. (1977). The CES-D Scale: A self-report depression scale for research in the general population. Applied Psychological Measurement, 1, 385-401.

Reilly, J. J., Armstrong, J., Dorosty, A. R., Emmett, P. M., Ness, A., Rogers, I., ... Children Study, T. (2005). Early life risk factors for obesity in childhood: Cohort study. BMJ (Clinical research ed.), 330, 1357.

Robinson, S., Marriott, L., Poole, J., Crozier, S., Borland, S., Lawrence, W., ... Southampton Women's Survey Study, G. (2007). Dietary patterns in infancy: The importance of maternal and family influences on feeding practice. The British Journal of Nutrition, 98, 1029-1037.

Rolls, B. J., Ello-Martin, J. A., \& Tohill, B. C. (2004). What can intervention studies tell us about the relationship between fruit and vegetable consumption and weight management? Nutrition Reviews, 62, 1-17.

Saavedra, J. M., Deming, D., Dattilo, A., \& Reidy, K. (2013). Lessons from the feeding infants and toddlers study in North America: What children eat, and implications for obesity prevention. Annals of Nutrition \& Metabolism, 62(Suppl 3), 27-36.

Sacco, L. M., Bentley, M. E., Carby-Shields, K., Borja, J. B., \& Goldman, B. D. (2007). Assessment of infant feeding styles among low-income African-American mothers: Comparing reported and observed behaviors. Appetite, 49, 131-140.

Siega-Riz, A. M., Deming, D. M., Reidy, K. C., Fox, M. K., Condon, E., \& Briefel, R. R. (2010). Food consumption patterns of infants and toddlers: Where are we now? Journal of the American Dietetic Association, 110, S38-S51. 
Skilton, M. R., Marks, G. B., Ayer, J. G., Garden, F. L., Garnett, S. P., Harmer, J. A., ... Celermajer, D. S. (2013). Weight gain in infancy and vascular risk factors in later childhood. Pediatrics, 131, e1821-e1828.

Skinner, J. D., Carruth, B. R., Bounds, W., Ziegler, P., \& Reidy, K. (2002). Do food-related experiences in the first 2 years of life predict dietary variety in school-aged children? Journal of Nutrition Education and Behavior, 34, 310-315.

Smithers, L. G., Brazionis, L., Golley, R. K., Mittinty, M. N., Northstone, K., Emmett, P., ... Lynch, J. W. (2012). Associations between dietary patterns at 6 and 15 months of age and sociodemographic factors. European Journal of Clinical Nutrition, 66, 658-666.

Stocks, T., Renders, C. M., Bulk-Bunschoten, A. M., Hirasing, R. A., van Buuren, S., \& Seidell, J. C. (2011). Body size and growth in 0- to 4-year-old children and the relation to body size in primary school age. Obesity reviews : an official journal of the International Association for the Study of Obesity, 12, 637-652.

Svensson, V., Sobko, T., Ek, A., Forssen, M., Ekbom, K., Johansson, E., ... Marcus, C. (2016). Obesogenic dietary intake in families with 1-yearold infants at high and low obesity risk based on parental weight status: Baseline data from a longitudinal intervention (Early STOPP). European Journal of Nutrition, 55, 781-792.

Taveras, E. M., Rifas-Shiman, S. L., Sherry, B., Oken, E., Haines, J., Kleinman, K., ... Gillman, M. W. (2011). Crossing growth percentiles in infancy and risk of obesity in childhood. Archives of Pediatrics \& Adolescent Medicine, 165, 993-998.

Thompson, A. L., Adair, L. S., \& Bentley, M. E. (2013). Pressuring and restrictive feeding styles influence infant feeding and size among a low-income African-American sample. Obesity (Silver Spring, Md.), 21, 562-571.

Thompson, A. L., \& Bentley, M. E. (2013). The critical period of infant feeding for the development of early disparities in obesity. Social Science \& Medicine (1982), 97, 288-296.

Thompson, F. E., \& Subar, A. F. (2013). Chapter 1-Dietary Assessment Methodology. In A. M. Coulston, C. J. Boushey, \& M. G. Ferruzzi (Eds.), Nutrition in the prevention and treatment of disease (third edition) (pp. 5-46)Academic Press.

U.S. Department of Health and Human Services and U.S. Department of Agriculture. (2015). 2015-2020 Dietary Guidelines for Americans. 8th
Edition. December 2015. Retrieved from http://health.gov/ dietaryguidelines/2015/guidelines/.

Wang, Y., Beydoun, M. A., Li, J., Liu, Y., \& Moreno, L. A. (2011). Do children and their parents eat a similar diet? Resemblance in child and parental dietary intake: Systematic review and meta-analysis. Journal of Epidemiology, 65, 177-189.

Wasser, H., Bentley, M., Borja, J., Davis Goldman, B., Thompson, A., Slining, M., \& Adair, L. (2011). Infants perceived as "fussy" are more likely to receive complementary foods before 4 months. Pediatrics, 127, 229-237.

Wasser, H. M., Thompson, A. L., Siega-Riz, A. M., Adair, L. S., Hodges, E. A., \& Bentley, M. E. (2013). Who's feeding baby? Non-maternal involvement in feeding and its association with dietary intakes among infants and toddlers. Appetite, 71, 7-15.

Wen, L. M., Simpson, J. M., Rissel, C., \& Baur, L. A. (2013). Maternal "junk food" diet during pregnancy as a predictor of high birthweight: Findings from the healthy beginnings trial. Birth (Berkeley, Calif.), 40, 46-51.

Wiltheiss, G. A., Lovelady, C. A., West, D. G., Brouwer, R. J., Krause, K. M., \& Ostbye, T. (2013). Diet quality and weight change among overweight and obese postpartum women enrolled in a behavioral intervention program. Journal of the Academy of Nutrition and Dietetics, 113, 54-62.

Worsley, A. (2002). Nutrition knowledge and food consumption: Can nutrition knowledge change food behaviour? Asia Pacific Journal of Clinical Nutrition, 11(Suppl 3), S579-S585 Australia.

Ystrom, E., Niegel, S., \& Vollrath, M. E. (2009). The impact of maternal negative affectivity on dietary patterns of 18-month-old children in the Norwegian Mother and Child Cohort Study. Maternal \& Child Nutrition, 5, 234-242.

How to cite this article: Kay MC, Wasser H, Adair LS, et al. Consumption of obesogenic foods in non-Hispanic black mother-infant dyads. Matern Child Nutr. 2018;14:e12482. https://doi.org/10.1111/mcn.12482 